\title{
A constitucionalidade das novas biotecnologias ao sistema agroalimentar brasileiro
}

\section{The constitutionality of new biotechnologies to the brazilian agrifood system}

\author{
DOI: $10.46814 / 1 a j d v 3 n 4-009$
}

Recebimento dos originais: 01/05/2021

Aceitação para publicação: 30/06/2021

\section{Ana Carolina de Morais Garcia}

Mestra em Direito Agrário - UFG

Coordenadora do Núcleo de Extensão, Pesquisa e Pós-Graduação do Centro Universitário Araguaia UniAraguaia

$$
\begin{aligned}
& \text { Av. T-10, n } 1047 \text { - Setor Bueno, Goiânia - GO, 74223-060 } \\
& \text { E-mail: anacmg31@ gmail.com }
\end{aligned}
$$

\section{RESUMO}

O presente artigo analisa a introdução das biotecnologias no campo brasileiro, a partir da modernização da agricultura e implantação da Revolução Verde, através de uma contextualização histórica. Trata sobre os impactos da biotecnologia, à soberania, a segurança alimentar e o reconhecimento constitucional do direito à alimentação.

Palavras-Chaves: Constitucionalidade, biotecnologia, alimentação

\section{ABSTRACT}

The present article analyzes the introduction of biotechnologies in the Brazilian field, from the modernization of agriculture and the implementation of the Green Revolution, through a historical contextualization. It deals with the impacts of biotechnology, sovereignty and food security and the constitutional recognition of the right to food.

Keywords: Constitutionality, biotechnology, food.

\section{INTRODUÇÃO}

A análise do processo de modernização da agricultura com a mecanização do campo abrange uma multiplicidade de acontecimentos. As questões ambientais e agroalimentares sofrem grandes impactos, com o aumento da produção de alimentos e a transformação da terra em mercadoria. Com a expansão das biotecnologias inúmeros debates surgiram sobre os impactos dos cultivares biotecnológicos, as divergências se apresentam no campo científico, político e econômico.

\section{A INTRODUÇÃO DA BIOTECNOLOGIA NA AGRICULTURA BRASILEIRA}

A implantação das biotecnologias no campo brasileiro adveio com a modernização da agricultura, que transformada em indústria passa adotar novas dinâmicas territoriais. Tais dinâmicas 
dizem respeito aos sistemas organizacionais e produtivos, que ao adotarem e aderirem ao discurso desenvolvimentista da Revolução Verde que foi empregado e disseminado à época, geram efeitos no campo e na cidade que buscam obedecer à lógica capitalista de organização, armazenamento, abastecimento e produção de alimentos.

A alteração dos processos biotecnologicos têm gerado impactos em diversos níveis, quais sejam: socioeconômicos, ambientais, agrários e no que tange à saúde humana. Nessa conjuntura se inclui o debate sobre a redução da biodiversidade e dos sistemas agrobiodiversos, onde pode se ver explicitamente a dimensão de tais impactos.

Contudo, a biotecnologia tem sido amparada juridicamente no contexto internacional, de forma que, com a sua introdução no território nacional foi admitida e apoiada sem entraves e dificuldades significativas. Este amparo se deu exatamente para possibilitar a disseminação da biotecnologia mundialmente, bem como garantir a segurança jurídica às empresas deste mercado.

A construção do regime jurídico da biotecnologia, portanto, representou a regulamentação das novas relações que delas surgiram, entre empresas e Estados. Tal regulamentação pode ser definida como uma nova forma jurídica, como se vê:[...] a forma jurídica do Direito nas sociedades capitalistas assemelha-se ao que é a forma da mercadoria para a Economia Política. Tal analogia constitui-se como um aporte útil para que se compreenda o processo de construção da forma jurídica correspondente às novas relações de produção instituída pela biotecnologia, e como essa forma, como verdadeira mercadoria, passou a ser produzida em série para os mais diversos países do mundo, que passaram a adotar assim uma mesma padronização em termos de seus respectivos sistemas de direito de propriedade intelectual (DIEHL, 2010, p. 78).

Ao tratar do regime jurídico específico da biotecnologia, uma nova forma jurídica, como foi demonstrada, destaca-se que o seu surgimento se deu no mesmo lugar onde se gerou as novas forças produtivas vinculadas à biotecnologia: os EUA. Pelo fato deste país adotar o sistema jurídico do common law, o Poder Judiciário é um dos principais responsáveis pela produção de normas e relações jurídicas, tendo a Suprema Corte em seu ápice (DIEHL, 2010, p. 78).

A Suprema Corte dos EUA, destarte, foi a responsável pela gestação pioneira da atual forma jurídica relacionada ao direito de propriedade industrial que se refere aos organismos geneticamente modificados (OGM). Tal gestação possibilitou que as corporações transnacionais patenteassem seres vivos geneticamente modificados, comercializando-os no mercado mundial mediante a possibilidade de imposição de preços monopolistas, de onde as empresas extraem superlucros a partir da forma de renda tecnológica (DIEHL, 2010, pp. 78-79).

Nesse sentido, para as corporações internacionais, a criação desta nova forma jurídica representou um verdadeiro meio de obtenção de maiores lucros mediante rendas tecnológicas 
propiciadas pelas patentes de OGM. Ademais, é preciso destacar que a fábrica escolhida para tanto não foi a Organização Mundial da Propriedade Industrial (OMPI), mas sim o GATT, que em português significa “Acordo Geral sobre Tarifas e Comércio" (DIEHL, 2010, p. 80).

Nesse contexto de formação do regime jurídico internacional da biotecnologia, de suma importância foi à criação do Acordo TRIPS, que em português quer dizer "Acordo sobre Aspectos dos Direitos de Propriedade Intelectual Relacionados ao Comércio", a saber:

[...] A partir da denominada Rodada Uruguai, que acabou por originar a OMC em 1994, logrou-se estabelecer dentro do GATT o Acordo TRIPS, que garantiu, em seu artigo 27, a possibilidade de patentear organismos vivos, sendo que a extensão desse direito poderia ser estabelecida livremente por cada país. Com isso, o enorme poder econômico, político e ideológico das corporações pôde ser utilizado país a país para "negociar" o regime jurídico que lhes fosse mais interessante, conforme seus objetivos geopolíticos (DIEHL, 2010, p. 80).

Contudo, importante destacar que a formação de um regime jurídico da biotecnologia no contexto internacional não abrange apenas o Acordo TRIPS, vai além e contempla a realidade e a posição de países considerados periféricos, a partir da CDB , por exemplo (DIEHL, 2010, p. 80).

Assim, o processo de formação do regime jurídico da biotecnologia e de seus elementos teve grande influência do TRIPS, o que significa o domínio dos EUA, cujo governo foi de suma importância ao se tratar da arquitetura jurídica daquele:

[...] O formato das leis sobre a propriedade intelectual adotado pelos países passou a ser determinado pelo conjunto de regras internacionais sobre propriedade industrial estabelecido no TRIPS, que foi basicamente desenhado pelas corporações internacionais e pelo governo dos EUA, e imposto por este último dentro da OMC, valendo-se da sua condição de superpotência imperialista já no período de globalização neoliberal, antes o desmoronamento da URSS e das repúblicas socialistas do leste europeu no início da década de 1990. Assim, ao longo desse período intensificaram-se as condições gerais de espoliação dos países periféricos, pois a partir do TRIPS as corporações transnacionais aumentaram os seus superlucros em virtude das rendas tecnológicas, que têm como uma de suas características principais a intensificação da troca desigual (DIEHL, 2010, p. 81).

Diante disso, pode-se dizer que o regime jurídico da tecnologia foi estabelecido num contexto internacional de domínio, sobretudo dos EUA, uma vez que esta potência teve grande influência tanto no TRIPS, como na OMC. Ademais, pode-se afirmar que, apesar da CDB dedicar esforços aos interesses de países periféricos, a hegemonia dos EUA permanece, pois já está consolidada na forma jurídica das relações produzidas a partir da biotecnologia.

Com isso, e retomando as relações de desigualdade e impactos que surgiram a partir do processo de modernização da agricultura no Brasil, pode-se dizer que tais desigualdades também se 
reproduziram num contexto internacional, a partir da regulamentação jurídica das relações advindas da biotecnologia.

O Brasil, por sua vez, se insere neste contexto, quando se trata das legislações adotadas sobre biotecnologia, OGMs, transgênicos, e afins, dado que a edificação do sistema jurídico de propriedade intelectual se deu, igualmente, por volta da década de 1990. Assim pode-se resumir o seu contexto de formação:

[...] No Brasil, todo o sistema jurídico de propriedade intelectual foi edificado nesse contexto, ao longo da década de 1990. Desde 1987 o governo estadunidense passou a pressionar o governo brasileiro a negociar com o Congresso Nacional uma lei de propriedade intelectual, conferindo assim a segurança jurídica necessária para que as corporações de biotecnologia pudessem ingressar no mercado nacional. Para isso, foram impostas inclusive sanções comerciais às exportações brasileiras, e o pleito obteve resposta favorável a partir do governo Collor, que, no dia seguinte à oficialização da Convenção sobre Diversidade Biológica - construída e consolidada na Conferência Internacional sobre Meio Ambiente Rio-92 -, enviou ao Congresso Nacional mensagem em favor do projeto de nova lei de propriedade industrial (PL 824/91), adequada ao patenteamento de organismos vivos (DIEHL, 2010, pp. 81-82).

Assim, o impeachment de Collor ocasionou o atraso da tramitação do projeto de lei, o qual foi priorizado pelo novo presidente Fernando Henrique Cardoso, que foi favorável à aprovação do mesmo. Isso explica, também, a promulgação das principais leis de propriedade industrial e intelectual na metade da década de 1990, com destaque à primeira Lei Brasileira de Biossegurança, à Lei de Patentes e Propriedade Intelectual e à Lei de Proteção de Cultivares (DIEHL, 2010, p. 81).

Diante disso, o Brasil passou a contemplar, a partir de seu ordenamento jurídico a existência de organismos geneticamente modificados, conferindo proteção aos direitos de propriedade industrial das grandes corporações de biotecnologia. A partir de então, o Instituto Nacional de Propriedade Intelectual (INPI) passou a se responsabilizar pela administração dos direitos e concessões de patentes, sendo que o art. 18, inciso III, da Lei de Propriedade Industrial proíbe o patenteamento de organismos vivos, com a exceção de microrganismos transgênicos, desde que obedeçam aos 3 requisitos de patenteabilidade e não representem simples descoberta (DIEHL, 2010, p. 82).

Nesse contexto, uma diversidade de setores da indústria e do governo se posicionou a respeito da introdução e da regulamentação da transgenia no Brasil, dentre eles a Comissão Técnica Nacional de Biossegurança, vinculada ao Ministério da Ciência, Tecnologia e Inovação.

Diante disso, faz-se necessário demonstrar, ainda que de maneira sucinta, a dimensão dos impactos da regulamentação da transgenia na biodiversidade, uma vez que, as consequências vão desde as relações trabalhistas e sociais, até a mais profunda alteração da biodiversidade local.

A adoção de um regime jurídico da transgenia no Brasil ocasionou uma diversidade de impactos nos ciclos produtivos. Os próprios produtores passaram a se utilizar destes mecanismos, advindos e 
introduzidos a partir do modelo da Revolução Verde, até mesmo para "remediar" processos naturais verificados em tais ciclos:

[...] Isso acontece, principalmente, devido à eliminação de predadores naturais dessas pragas. Para combater as que destroem as lavouras de monocultura, os produtores lançaram mão do uso intensivo de agrotóxicos - inseticidas, fungicidas químicos e herbicidas - para eliminação de ervas indesejáveis conhecidas como ervas daninhas que crescem, rapidamente, no meio das plantações. Há de se registrar que, na medida em que se utilizam tais insumos para eliminação das pragas, as mesmas se tornaram mais resistentes, demandando cada vez mais o uso de agrotóxicos (ANDRADES; GANIMI, 2007, p. 50).

Neste sentido, é possível concluir que o processo de modernização da agricultura no Brasil acarretou a transformação deste setor em parte da indústria, desconsiderando a dimensão do que tal agricultura realmente abriga, ou seja, embora seja considerada de acordo com a posição hegemônica ocidentalizada como mero setor industrial, ela tem ligação direta à alimentação da população, à subsistência, à produção de gêneros que vão além dos alimentícios.

Com o discurso da Revolução Verde tal processo se intensificou. O Brasil passou a adotar seu modelo como o melhor caminho para a solução de uma série de questões que afetam as vidas nas décadas de 50, 60 e 70. Contudo, o discurso da fome comoveu e ganhou forças, sendo implementado no Brasil, a base do modelo agroexportador.

A partir disso, novas portas foram abertas à introdução de novos mecanismos. Com o domínio dos EUA sobre o Acordo TRIPS, bem como sua influência no contexto de criação da OMC, o modelo da biotecnologia passou a fazer parte de uma série de países, tendo a sua regulamentação jurídica proporcionada a aceitação de OGM, de transgênicos, dentre outros organismos, no que tange ao consumo de alimentos.

Os transgênicos e os OGM, assim como outras substâncias químicas, apresentam sérios riscos à saúde humana, seja mediante o consumo de alimentos, seja através do próprio processo de produção. Além disso, como exposto, os riscos vão além e atingem as relações de trabalho e sociais, a estrutura agrária do Estado que aceita a introdução da biotecnologia em seu modelo, bem como a biodiversidade, a partir dos impactos ambientais.

Contudo, a crítica que se faz é que, ao se tratar da biodiversidade, esta se tornou, também, um elemento mercantilizável, consumível. Assim como houve a transição da agricultura para indústria, a biodiversidade foi alvo deste modelo que se consolidou concomitantemente ao processo de modernização surgido a partir da década de 50.

As grandes potências, assim como as instituições dominantes, nesse contexto atuam no sentido da apropriação capitalista da biodiversidade, como demonstra a geógrafa Maria Geralda de Almeida: 
[...] De acordo com as instituições dominantes, e manifestando sobretudo os interesses da indústria químico-farmacêutica, a chave para a conservação da biodiversidade está na utilização dos recursos, de modo a garantir sua conservação a longo prazo; ou seja, os padrões de significado-uso dos recursos naturais são de grande importância na teorização e quantificação da biodiversidade. $\mathrm{O}$ dito uso, na opinião daquelas instituições, deve-se fundamentar no conhecimento científico da biodiversidade, em sistemas apropriados de administração e em mecanismos adequados que estabeleçam os direitos da propriedade intelectual e que protejam as descobertas passíveis de comercialização. A Estratégia Global para a Biodiversidade, elaborada em 1991, apoiando-se na tríade conhecer-salvar-usar, tem promovido por diversos meios a caça aos genes, justificando-a como necessária para salvar a natureza, pois está neles, a fonte dos benefícios e das ganâncias da conservação (ALMEIDA, 2003, p. 79).

Diante disso, pode-se compreender que a introdução do regime jurídico da biotecnologia no Brasil também representa a sua mais real forma de apropriação capitalista da biodiversidade. Os impactos aconteceram e acontecem em diversos níveis.

Contudo, ainda que haja esforços e conhecimento de tais impactos e do problema como um todo, o jogo vai além, uma vez que, envolve relações de poder não só entre potências e Estados, como também no que tange aos próprios incentivos fiscais e monetários do próprio país em determinados setores.

Portanto, a biotecnologia, neste contexto, embora seja aceita como sinônimo de desenvolvimento e progresso econômico há uma série de impactos que reproduz, afetando diversos aspectos inclusive no que se refere à soberania e segurança alimentar. Porém, conclui-se que é um problema estrutural, de construção histórica, pois não haveria consolidação e domínio se o Estado não apoiasse. É, destarte, a cultura da racionalidade colonial nas decisões do Estado.

\section{SOBERANIA E SEGURANÇA ALIMENTAR}

A soberania alimentar cuida da dimensão econômica, especialmente no que concerne às relações econômicas internacionais, com o princípio de que os interesses de um povo não podem se submeter aos interesses do estrangeiro, ou seja, este tema deve seguir as regras e se submeter à seara de decisão política, e cada nação tem de compreendê-lo como aspecto estratégico de seu desenvolvimento (ZIMMERMANN, 2008, p. 12).

No segundo Fórum Mundial sobre Soberania Alimentar, realizado em Cuba em 2001, conceituou-se a soberania alimentar como o direito dos povos a definir as políticas e estratégias sustentáveis de produção, distribuição e consumo de alimentos que garantam o direito à alimentação para a população, baseado na pequena e média produção, respeitando a diversidade, as culturas dos camponeses, pesqueiros, indígenas e o modo de produção no qual a mulher desempenhava um papel fundamental. 
O conceito de segurança alimentar está ligado ao acesso contínuo e permanente ao alimento, de presentes e futuras gerações. JUNGES (2014) conceitua a segurança alimentar, relacionando-a com a sustentabilidade e a forma de produção dos alimentos, a utilização adequada dos recursos naturais não renováveis com intuito de assegurar a sustentabilidade da produção e qualidade de vida para gerações futuras.

Em linhas gerais a soberania alimentar pode ser entendida como a autonomia, a capacidade e a detenção de meios que cada país possui para a produção de alimentos.

A Segurança Alimentar e Nutricional pressiona o modelo atual de produção de alimentos na medida em que a tecnologia da empresa rural representa um mecanismo hegemônico de atuação do capital no campo. Visa a garantia e o acesso permanente e regular a alimentos seguros e saudáveis, a produção social e ambientalmente sustentável nos contextos culturalmente diversos.

Destarte, a soberania alimentar está ligada à soberania econômica, política e cultural dos povos. Estabelece o direito das nações e dos povos a produzir, distribuir e consumir os alimentos em observância à diversidade cultural existente. O conceito de Segurança Alimentar e Nutricional, faz parte do Direito Humano à Alimentação Adequada.

O novo conceito de Segurança Alimentar e Nutricional adotado no Brasil diz respeito ao atendimento integral das necessidades básicas, a fim de assegurar uma vida humana plena e digna. Constitui o conceito, também, o acesso físico e econômico, regular e permanente aos alimentos seguros do ponto de vista higienicosanitário, livre de substâncias químicas e nocivas à saúde humana. Referese, ainda, ao alimento produzido de forma saudável, com base em um modelo de produção sustentável e seguro, de acordo com os critérios ambientais e, sobretudo, culturalmente referenciado.

Para VALENTE (2002), os elementos que definem a soberania alimentar possibilitam uma alimentação saudável, além de não apresentar riscos ao meio ambiente e à biodiversidade. Diante disso, existem caminhos que possibilitam a efetivação da soberania alimentar, como, a título de exemplo, os alimentos orgânicos.

No entanto, faz-se necessário ressaltar que no Brasil, não há, ainda, a democratização do acesso a alimentos advindos da produção orgânica, ou seja, embora seja saudável e respeite o princípio da soberania alimentar, nem todas as classes da população têm acesso.

Isso se deve ao alto custo de alimentos orgânicos, o que faz com que a população não tenha escolha, a não ser o consumo de produtos economicamente acessíveis, portanto, pertencentes à produção em larga escala que, para obedecer a sua lógica, utiliza-se de substâncias químicas, como os agrotóxicos, dentre outros agrovenenos.

Nesse sentido, importantes as considerações do Professor Gladstone Leonel Júnior: 
[...] a agricultura predominante, ainda, é aquela desenvolvida com os insumos petrodependentes, formadas nos latifúndios e responsável pelo desenvolvimento, principalmente, por meio do monocultivo à exportação. A falta de biodiversidade decorrente do desequilíbrio ambiental gerado pelas monoculturas contribui para um maior empobrecimento do solo e utilização de agrotóxicos, para controlarem as ervas daninhas, os insetos e as doenças das plantas [...] Agricultura que é controlada pelas grandes transnacionais, as quais direcionam a produção para as necessidades do mercado. Na agricultura química convencional, o importante é o produtivismo, o qual diante de uma lógica mecanicista e mercantilista, ignora os diversos impactos e os custos desse tipo de produção (LEONEL JÚNIOR, 2016, p. 73).

Para FERNANDES (2009), o debate da soberania alimentar toca em diversas questões, como a fome, o alimento, as políticas públicas, o modelo de desenvolvimento, as relações sociais, a tecnologia, o trabalho, o governo, o campesinato, o agronegócio, dentre outros.

Ainda de acordo com FERNANDES (2009), defender a soberania alimentar e transformá-la em política pública é assumir uma posição contrária às commodities, dada a relação existente entre as agriculturas agroexportadoras do agronegócio e a fome no mundo. Significa, também, defender a qualidade dos alimentos para o bem da saúde pública, utilizando tecnologias sustentáveis.

Segundo ZIEGLER (2013), a partir da década de 90, com o processo de globalização, houve a abertura de mercados e a comercialização de bens e mercadorias, o que acarretou o desaparecimento da soberania alimentar por parte dos países pobres do Sul, além do aumento das vítimas de subalimentação e da fome.

Diante disso, compreende-se que o processo de mercantilização da terra, somado ao uso das novas tecnologias trazidas pela Revolução Verde, além de gerar impactos ambientais e especificamente à perda e à redução da biodiversidade, também está inserido em um jogo de poderes, onde os interesses econômicos prevalecem, em detrimento às demandas sociais, quanto se trata de soberania alimentar.

Nesse contexto, para FERNANDES (2009), a soberania alimentar só pode ser política de governos democráticos que não estejam vinculados às corporações nacionais e transnacionais, uma vez que, tais corporações colocam seus interesses acima dos da sociedade, transformando os alimentos em pura mercadoria, sem observância à soberania alimentar. Há uma diferença grande entre as duas formas de organização que produzem alimentos para a sociedade: o agronegócio e o campesinato.

Nessa perspectiva, o agronegócio é soberano no que se refere às questões agrícolas e defende a soberania alimentar, por se tratar de uma política compensatória que garante parcialmente alimentos industrializados para a população carente, mas não garante o direito de produzir alimentos para a população que sofre com a fome.

Quanto ao campesinato, sua concepção de alimento está vinculada ao território, ou seja, a ideia do campesinato se refere à disputa territorial no campo da produção agrícola e volta-se às políticas públicas. 
Segundo Valente, a origem do conceito de segurança alimentar se deu na Europa, no início do século XX, associado à segurança nacional e à capacidade de produção de alimentos, como forma de não-vulnerabilidade a embargos de cunho político ou militar.

Esse conceito tornou-se evidente no cenário internacional a partir da crise de escassez de alimentos ocorrida entre os anos de 1972 e 1974, associada a uma política de criação e manutenção de estoques nacionais de alimentos e da I Conferência Mundial de Alimentação, organizada pela Food and Agriculture Organization (FAO), órgão integrante da Organização das Nações Unidas (ONU).

Nesse momento, a segurança alimentar se afasta de uma perspectiva de direito humano para uma perspectiva produtivista e neomalthusiana, com ênfase na produção, em detrimento ao direito humano ao alimento. Na década de 1980, com a superação da crise, a visão que se formou foi que os problemas da desnutrição decorriam de demanda e distribuição.

Uma vez que, o conceito de segurança alimentar surgiu no contexto de escassez alimentar, é possível compreender que este se liga intimamente às questões humanas e ao direito humano à alimentação. Nessa perspectiva, a FAO, atua no combate à fome e à pobreza, promove o desenvolvimento agrícola, a melhoria da nutrição, a busca da segurança alimentar e o acesso de todas as pessoas, em todos os momentos, aos alimentos necessários para uma vida saudável. Reforça a agricultura e o desenvolvimento sustentável, como estratégias para aumentar a produção a longo prazo e o acesso de todos aos alimentos, ao mesmo tempo em que preserva os recursos naturais.

Ao final da década de 1980 e dos anos 90, o conceito de segurança alimentar é ampliado para inclusão de questões relacionadas à qualidade sanitária, biológica, nutricional e cultural dos alimentos. Segundo SEN (1981), tal ampliação ocorreu na Conferência Internacional de Nutrição promovida pela FAO e pela Organização Mundial da Saúde (OMS).

A partir de então, a perspectiva humanística do conceito relacionado à segurança alimentar domiciliar foi incorporada ao conceito de segurança alimentar. Para VALENTE (1996), a alimentação é um processo complexo de transformação da natureza em gente, em seres humanos, ou seja, em humanidade.

O conceito de segurança alimentar foi ampliado a fim de valorizar a oferta e o acesso à alimentação de qualidade, à assistência básica à saúde (abastecimento de água, saneamento, saúde pública) e o cuidado promovido no lar aos membros da família (carinho, atenção, preparo do alimento, aleitamento materno, estimulação psicossocial, informação, apoio educacional, dentre outros).

A partir de então, o referido conceito se fortaleceu como direito humano econômico, social e cultural e passou a se expressar em movimentos nacionais e internacionais ligados às questões da alimentação e da nutrição como questão de cidadania. 
Portanto, realizados os apontamentos conceituais acerca da soberania e da segurança alimentar, compreende-se que sua construção se deu historicamente, tendo a FAO atuado significativamente neste sentido. Além disso, para que tais princípios sejam devidamente efetivados, faz-se necessário a implementação de políticas públicas voltadas para este objetivo.

\section{O RECONHECIMENTO CONSTITUCIONAL DO DIREITO À ALIMENTAÇÃO}

Na Assembleia Geral das Nações Unidas, em 10 de dezembro de 1948, a Declaração Universal dos Direitos Humanos proclamou alguns direitos fundamentais dos seres humanos, dos quais ressaltase o artigo XXV, inciso 1, que preceitua:

[...] Todo ser humano tem direito a um padrão de vida capaz de assegurar-lhe, e a sua família, saúde e bem-estar, inclusive alimentação, vestuário, habitação, cuidados médicos e os serviços sociais indispensáveis, e direito à segurança em caso de desemprego, doença, invalidez, viuvez, velhice ou outros casos de perda dos meios de subsistência em circunstâncias fora de seu controle.

Dentre os direitos elencados na Declaração Universal dos Direitos Humanos, destaca-se o direito à alimentação como direito humano fundamental.

No Brasil o direito à alimentação foi introduzido como direito social através da Emenda Constitucional n 64/2010, que alterou a redação do artigo $6^{\circ}$ da Constituição da República Federativa do Brasil (CRFB), o qual dispõe o seguinte:

Art. $6^{0}$ São direitos sociais a educação, a saúde, a alimentação, o trabalho, a moradia, o transporte, o lazer, a segurança, a previdência social, a proteção à maternidade e à infância, a assistência aos desamparados, na forma desta Constituição.

CESARINO JUNIOR, apud ARCÁ define a Legislação Social como:

[...] o conjunto de normas emanadas do Estado, disciplinando as relações que intercedem entre as classes capitalistas e as classes trabalhadoras, acrescentando: Social se diz essa legislação, seja porque se refere a relações entre classes ou entre indivíduos de classe diversa, seja porque não tem atitudes, caracteres, e fins jurídicos, mas sim de tutela e proteção, de disciplinamento de situações de fato e de relações sociais extrajudiciais, as quais superam e em parte contradizem a premissa da absoluta igualdade de direito, que é imprescindível à compreensão das relações judiciais de direito privado e a noção de sujeição que também é imprescindível à compreensão das relações que prendem o indivíduo de qualquer classe ao Estado.

Através do rol exemplificativo do artigo $6^{\circ}$, a Constituição consagrou direitos sociais, econômicos e culturais, os quais estão classificados como direitos de segunda dimensão ou segunda geração.

Os direitos de segunda dimensão, de acordo com George Marmelstein: 
[...] Impõem diretrizes, deveres e tarefas a serem realizadas pelo Estado, no intuito de possibilitar aos seres humanos melhores qualidade de vida e um nível de dignidade como pressuposto do próprio exercício da liberdade. Nessa acepção, os direitos fundamentais de segunda geração funcionam como uma alavanca ou uma catapulta capaz de proporcionar o desenvolvimento do ser humano, fornecendo-lhe as condições básicas para gozar, de forma efetiva, a tão necessária liberdade.

Dentre os direitos sociais, destaca-se o direito ao mínimo existencial que deve ser tratado como um direito fundamental, atribuído ao título dos direitos e garantias fundamentais sem os quais não seria possível a existência. Refere-se ao mínimo, aos direitos e as necessidades essenciais da vida, as condições mínimas e essenciais à sobrevivência humana.

No ordenamento jurídico brasileiro igualmente se destaca a proibição do retrocesso, o princípio da dignidade da pessoa humana, o princípio da máxima efetividade e o princípio do Estado democrático de direito. Apesar do que dispõe a Constituição Federal a respeito do tema, cumpre ressaltar que em 2006, a Lei Orgânica n 11.346/2006 criou o Sistema Nacional de Segurança Alimentar e Nutricional - SISAN - regulamentando o direito humano à alimentação adequada e resguardando o direito à segurança alimentar e nutricional da população.

O direito à alimentação é um exemplo de como as sociedades modernas podem aprender, a partir de suas próprias experiências e como a luta por reconhecimento pode gerar novos direitos. Toda sociedade aprende nesse processo. Como parte do aprendizado histórico há o acúmulo semântico: a fome e a segurança alimentar foram redefinindo os significados. Isso permitiu o avanço das discussões em torno da fome e o enfrentamento de conceitos, que desrespeitavam a linguagem de liberdade e igualdade, cerne do constitucionalismo.

A referida lei regulamentou o direito à alimentação adequada e a segurança alimentar e nutricional da população através do SISAN, com a integração de órgãos da União, Estados, Distrito Federal, Municípios e instituições privadas.

Além disso, esta lei trouxe os princípios que regem o SISAN, dentre esses estão: universalidade e equidade no acesso à alimentação adequada, preservação da autonomia e do respeito à dignidade da pessoa humana, participação social na formulação, execução, acompanhamento, monitoramento e controle das políticas e dos planos de segurança alimentar e nutricional e transparência dos programas, das ações e dos recursos públicos e privados.

De acordo com o artigo $4^{\circ}$, IV, da Lei 11.346/2006, a segurança alimentar e nutricional abrange a qualidade biológica, sanitária, nutricional e tecnológica dos alimentos, seu aproveitamento com estímulos às práticas alimentares e saudáveis, respeitando as diversidades étnicas, raciais e culturais da população. 
$\mathrm{O}$ ato de alimentar-se para o ser humano está ligado a sua cultura, a sua família, a seus amigos e a festividades coletivas. Ao alimentar-se junto de amigos, de sua família, comendo pratos característicos de sua infância, de sua cultura, o indivíduo se renova em outros níveis além do físico, fortalecendo também sua saúde mental e sua dignidade humana. Assim, o direito à alimentação passa pelo direito de acesso aos recursos e meios para produzir ou adquirir alimentos seguros e saudáveis que possibilitem uma alimentação de acordo com os hábitos e práticas alimentares de sua cultura, de sua região ou de sua origem étnica.

A lei supracitada trouxe as expressões: "práticas alimentares e estilos de vida saudáveis" e "alimentação adequada", abrindo margem ao questionamento a respeito do que signifique cada expressão, uma vez que, cada sociedade adequa o seu modo de vida de acordo com suas concepções culturais.

Nesse sentido, de suma importância as considerações de VALENTE (2002):

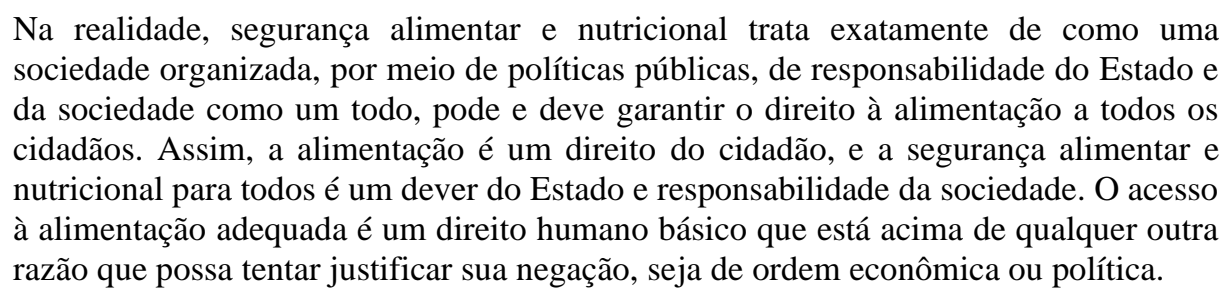

Assim, compreende-se que o direito à alimentação é um direito fundamental, cuja garantia é de responsabilidade do Estado e da sociedade. Da mesma forma, a soberania e a segurança alimentar são direitos humanos, e transcendem o conceito de direito à alimentação, uma vez que, consideram o ato de alimentar-se como uma prática cultural, envolvendo mais do que o mero processo biológico de ingerir alimentos.

Porém, é preciso ressaltar que o desenvolvimento científico, ao modernizar a agricultura e mercantilizar a terra, trouxe mecanismos biotecnológicos para o campo, dentre eles estão o objeto de pesquisa: os OGM e os transgênicos.

O desenvolvimento científico (e tecnológico), portanto, são transformados em formas de conhecimento hierarquicamente superiores, na intenção de garantir a lucratividade empresarial. Sendo assim, o debate dessas questões não observa a vertente da Ciência que prioriza o respeito à soberania dos povos ou que busque pela preservação ambiental e pela justiça social (LEONEL JÚNIOR, 2016, p. 58-59).

Nesse viés, faz-se necessário trazer as considerações de Maria João Estorninho:

O tema dos Organismos Geneticamente Modificados confronta o ser humano com as suas convicções mais profundas, os seus hábitos milenares e os seus medos, racionais e irracionais. A 
verdadeira revolução que a produção industrial de OGM provocou veio pôr em causa técnicas e hábitos arreigados dos agricultores, tais como o de guardar e reutilizar a semente. Os novos produtos destinados ao consumo humano, nos quais as fronteiras entre o alimento e medicamento são cada vez mais difíceis de traçar, subvertem hábitos alimentares tradicionais e surgem cenários só concebíveis, até há bem pouco tempo, como ficção científica.

Portanto, diante da situação apresentada, quando se fala no cultivo de organismos geneticamente modificados e transgênicos, com a implementação de novas biotecnologias no sistema agroalimentar, é preciso levar em consideração que tais práticas geram impactos à biodiversidade, principalmente quando se trata de sua conservação.

As técnicas utilizadas pela biotecnologia se diferem das práticas adotadas pelos camponeses, uma vez que, estes têm como base seus conhecimentos tradicionais. Com o processo de desenvolvimento científico, já abordado nesta seção, além de haver a inserção de novos modos de produção de alimentos, houve também a consolidação da ideia de que tais práticas são hierarquicamente superiores, não conferindo a mesma validade aos modos tradicionais produtivos.

Nessa mesma acepção, LEONEL JÚNIOR (2016) traz a debate esta questão, conjuntamente com o tema da transgenia:

[...] Os experimentos transgênicos diferem, substancialmente, do melhoramento secular de sementes realizado pelos camponeses/as. Há uma desconsideração à valorização dessas práticas feitas no decorrer da história pelos próprios agricultores, em que escolhiam as melhores plantas para promover o cruzamento entre as espécies semelhantes, feito naturalmente, ou para retirar as mudas e as sementes com o intuito de melhorá-las. A transgenia não age assim. $\mathrm{O}$ modo de produção biotecnológico afasta o produtor como protagonista e conhecedor do processo. As modificações genéticas são feitas por meio de laboratórios tendo um elevado custo financeiro. As sementes alteradas seguem a lógica de mercado e não da natureza, sendo suas modificações realizadas para uma maior lucratividade das empresas que atuam no setor (LEONEL JÚNIOR, 2016, p. 59).

Destarte, com base no exposto, é possível concluir que embora o direito à alimentação e o princípio da soberania e da segurança alimentar sejam direitos de caráter fundamental, sendo responsabilidade do Estado e da sociedade suas garantias, com a inserção de novas técnicas de produção de alimentos que obedecem e agem de acordo tão-somente com a lógica do mercado, ainda existem dificuldades e entraves para o efetivo acesso à alimentação saudável, sendo os OGM e os transgênicos um destes problemas, dados os impactos de seus modos de produção (não sustentável).

\section{CONCLUSÃO}

O processo de modernização da agricultura foi pautado em um discurso desenvolvimentista que visava à produtividade e a produção em larga escala. O que se tornou possível a partir da introdução 
de mecanismos industriais na agricultura, e ocasionou diversas consequências, dentre as quais, a concentração fundiária em detrimento do acesso a terra, a perda da autonomia dos agricultores aos ciclos produtivos, a submissão e a condição de dependência da agricultura à indústria e os riscos a saúde humana e ao meio ambiente ecologicamente equilibrado.

A partir da transformação da agricultura em indústria a terra passou a ser vista como mercadoria. Tal transição ocorreu a partir da modificação das concepções de diversas categorias da sociedade, devido a grande influência do pensamento hegemônico ocidental e o modo de produção capitalista introduzido na economia brasileira.

O complexo agroindustrial se sedimentou a partir do momento que a agricultura deixou ser autônoma e passou a ser subordinada aos modos de produção capitalista, foi integrada aos outros setores, a partir da implantação de insumos e mecanismos industriais em várias fases dos ciclos produtivos. Para a consolidação do complexo agroindustrial, partiu-se da ideia de que o espaço agrário brasileiro enfrentava dificuldades para o seu desenvolvimento, e que era necessário à adoção da Revolução Verde para alcançar esse fim, mas para isso era preciso acabar com a agricultura tradicional.

Embora o processo de modernização da agricultura englobe a formação dos complexos agroindustriais, e estes sejam hegemonicamente positivos, é necessário ressaltar que este foi precursor histórico da desigualdade social, da concentração fundiária que ocasionou a má distribuição de terras no território brasileiro, o êxodo urbano, a redução da biodiversidade e os impactos aos biomas brasileiros. Além disso, foram responsáveis pela mecanização do campo, com o intuito de aumentar a produtividade e a produção em larga escala que vai na contramão da segurança e da saúde alimentar.

Nessa conjuntura, a Revolução Verde vem determinar o modelo de produção adotado pelo Brasil, com um discurso dominante de aumento da produtividade com o intuito de resolver o problema da fome. No entanto, diversos fatores estavam por traz desse discurso. O modo de produção capitalista imposto pela Revolução Verde, a partir da introdução de novas biotecnologias, o uso de insumos químicos, agrotóxicos, organismos geneticamente modificados e outros elementos que visavam acelerar o processo e a produtividade, visando atingir uma produção em larga escala.

Sendo assim, percebeu-se que nesse contexto histórico-político-social da época o discurso da Revolução Verde foi validado e aceito pelo Estado brasileiro, em razão desse modo de produção a oferta. O consumo dos produtos agrícolas no Brasil têm se mostrado em dois seguimentos: o aumento da demanda no mercado externo commodities e as referentes ao mercado interno que buscam quantidade, qualidade e preço. Diante desses seguimentos há uma tensão entre o consumo mundial de commodities e a soberania alimentar. 
Embora a biotecnologia seja aceita como sinônimo de desenvolvimento e progresso econômico há uma série de impactos provocados ao meio ambiente, à saúde humana e animal apesar das pesquisas se mostrarem divergentes quanto aos benefícios e malefícios provocados pela inserção destas.

Como podemos perceber há um crescente aumento da produção nos cultivos de culturas biotecnológicas no cenário mundial, em que se destacam algumas empresas, as quais exercem um oligopólio que vai desde a produção até a distribuição dos alimentos. Essas multinacionais da engenharia genética dominam o mercado agroalimentar controlando os preços, o comércio dos alimentos e os setores essenciais da agroindústria como as sementes, os adubos, os pesticidas, os herbicidas, a estocagem, o transporte, dentre outros. E como muito bem afirma o autor Pat Roy Mooney se você domina as sementes, você controla a humanidade.

Sendo assim, é possível concluir que embora o direito à alimentação e o princípio da soberania e da segurança alimentar sejam direitos de caráter fundamental e de responsabilidade do Estado e da sociedade, as garantias com a inserção de novas técnicas de produção de alimentos que obedecem e agem de acordo tão-somente com a lógica do mercado, provocam dificuldades e entraves para o efetivo acesso à alimentação saudável, dentre as quais os OGM e transgênicos estão inseridos pelos impactos causados por seus modos de produção. 


\section{REFERÊNCIAS}

ALMEIDA, Maria Geralda de. Cultura ecológica e biodiversidade. In: Mercator - Revista de Geografia UFC, ano 02, número 03, 2003.

ANDRADES, Thiago Oliveira; Rosângela Nasser Ganimi. Revolução verde e a apropriação capitalista. In: CES Revista, v.21. Juiz de Fora, 2007.

DIEHL, Diego Augusto. Espaços Territoriais Especialmente Protegidos como Instrumentos Jurídicos de Defesa dos Povos da Amazônia: Uma análise dos riscos socioambientais da expansão da soja geneticamente modificada. Dissertação de Mestrado. Belém: Programa de Pós-Graduação em Direito do Instituto de Ciências Jurídicas da Universidade Federal do Pará, 2010.

FERNANDES, Bernardo Mançano. Sobre a tipologia de territórios. In SAQUET, Marcos Aurélio. SPOSITO, Eliseu Savério (Orgs.) Territórios e Territorialidades. São Paulo, Expressão Popular, 2009. Disponível em: http://www.acciontierra.org/IMG/pdf/BERNARDO_TIPOLOGIA_DE_TERRITORIOS.pdf>. Acesso em: 10 mai. 2018.

JUNGES, J. Bioética e Meio Ambiente num contexto de América Latina. Revista Redbioética/UNESCO, v. 1, n. 9, 2014.

JÚNIOR, Cesarino. Direito Social: denominação, conceito e conteúdo. inaugural do curso de Legislação Social. Disponível em: file://C:/Users/AnaCarolina/Downloads/65900Texto\%20do\%20artigo-87274-1-10-20131125.pdf

JÚNIOR, Gladstone Leonel. Direito à agroecologia: a viabilidade e os entraves de uma prática agrícola sustentável / Gladstone Leonel Júnior - 1ª ed. - Curitiba; Ed. Prismas, 2016.

MARMELSTEIN, George. Curso de direitos fundamentais. São Paulo: Altas, 2008.

SAQUET Marcos Aurelio Saquet, Eliseu Savério Sposito (organizadores) Territórios e territorialidades: teorias, processos e conflitos 1.ed. São Paulo : Expressão Popular : UNESP. Programa de Pós-Graduação em Geografia, 2008.

SEN, A. Poverty and Famines: An Essay on Entitlement and Deprivation, Oxford, Oxford University Press, 1983.

VALENTE, F. L. S. Do combate à fome à segurança alimentar e nutricional: o direito humano à alimentação adequada. Revista de Nutrição PUCCAMP, v. 10, n. 1, pp. 20 - 36, jan./jun., 1997.

VALENTE, Flavio Luiz Schieck. Direito Humano à alimentação: desafios e conquistas (organizador) Flávio Luiz Schieck Valente. - São Paulo: Cortez, 2002.

ZIEGLER, Jean. Destruição em massa geopolítica da fome. Tradução de José Paulo Neto. $1^{\text {a }}$ ed. São Paulo: Cortez, 2013.

ZIMMERMANN, Clóvis Roberto (rel.). Direito Humano à Alimentação e Terra Rural. Plataforma Dhesca Brasil. Curitiba: INESC, 2008. 